\title{
Ezaugarrien kronologiaren garrantzia: -ki-dun indikatiboko NOR-NORI saileko adizkien historia pixka bat ${ }^{1}$ \\ On the importance of chronology: A short history of the bivalent intransitive $(A B S / D A T)$ auxiliary verbs with -ki-
}

\author{
Urtzi Reguero-Ugarte*
}

Universidad del País Vasco/Euskal Herriko Unibertsitatea (UPV/EHU)

\begin{abstract}
In this paper, a special kind of bivalent intransitive (ABS/DAT) conjugation, characterized by a marker -ki-, as in dakit (Standard zait) or zekion (Standard zitzaion) is analysed diachronically and chronologically. These forms of ABS/DAT auxiliary appear in some variants of High-Navarrese. This characteristic was thought to be an archaism, a continuation of an old aoristic periphrasis, but the paper presents new evidence leading to reject this hypothesis and to offer a new one, according to which this characteristic is an innovation based on intransitive conjugation.

KEYWORDS: High-Navarrese, intransitive plus dative conjugation, dialectology, chronology, diachrony, texts.

LABURPENA: Artikulu honetan Nafarroa Garaiko hizkera batzuetan agertzen diren dakit 'zait', zekion 'zitzaion' gisako indikatiboko NOR-NORI saileko adizkiak aztertzen dira ikuspuntu diakroniko eta kronologiko batetik. Mendez mende, adizki horien agerraldiak eta lekukotasunak aztertzen dira, XVI. mendeko testu zaharrenetatik abiatu eta XX. mende bitarteko testigantzetara bitartean. Orain arte ezer gutxi ikertu da gaiaz eta, oro har, aoristoarekin lotutako arkaismotzat hartu izan da. Halere, saio honetan hipotesi horren puntu ahulak aurkezten dira; besteak beste, orainaldian ere agertzea edo NOR 3. pertsona denean bakarrik erabiltzea. Horren ordez, beraz, bestelako proposamen bat aurkeztu eta Nafarroako erdiguneko hizkera batzuek egindako berrikuntza bat dela defendatzen da. Bidenabar, ezangarri dialektalen azterketa xeheek dialektologia diakronikoan egin dezaketen ekarpena ere aldarrikatu nahi da.
\end{abstract}

HITZ GAKOAK: goi-nafarrera, Nor-Nori, dialektologia, kronologia, diakronia, testuak.

1 Saio hau "Monumenta Linguae Vasconum (V): periodizazioa eta kronologia» (FFI: 2016-76032-P) proiektuaren eta «Historia de la lengua vasca y lingüística histórico-comparada» (IT 698-13) ikerketa taldearen baitan egin da. Biziki eskertu behar ditut Ricardo Gómez-López, Borja Ariztimuño, Patxi Salaberri eta $A S J U$ ko ebaluatzaile anonimoak lan honen aurreko bertsio bat irakurri eta egindako oharrengatik. Esan gabe doa hutsak nireak baizik ez direla.

* Harremanetan jartzeko / Corresponding author: Urtzi Reguero-Ugarte. Hizkuntza eta Literaturaren Didaktika Saila - Hezkuntza eta Kirol Fakultatea (UPV/EHU). Juan Ibáñez de Sto. Domingo kalea, 1 (01006 Vitoria-Gasteiz) - urtzi.reguero@ehu.eus - https://orcid. org/0000-0003-1549-0738

Nola aipatu / How to cite: Reguero-Ugarte, Urtzi (2020 [2022]). «Ezaugarrien kronologiaren garrantzia: -ki-dun indikatiboko NOR-NORI saileko adizkien historia pixka bat», ASJU, 54 (1-2), 251-263. (https://doi.org/10.1387/asju.23022).

Jasoa/Received: 2021-01-27; Onartua/Accepted: 2021-06-21. Online argitaratua / Published online: 2021-08-09

ISSN 0582-6152 - eISSN 2444-2992 / (c) 2022 Instituto-Seminario de Filología Vasca «Julio de Urquijo» (UPV/EHU)

(c) (i) (-) Lan hau Creative Commons Aitortu-EzKomertziala-LanEratorririkGabe 4.0 Nazioartekoa

cc) 


\section{Sarrera}

Saio honetan Nafarroa Garaiko hizkera batzuetan agertzen diren dakit 'zait', zekion 'zitzaion' gisako indikatiboko NOR-NORI saileko adizkiak izango ditut aztergai.

Ezer gutxi aztertu da, orain arte, ezaugarri hori; eta dugun informazio bakarra goi-nafarrera — dela sinkronikoki dela diakronikoki- aztertu duten ikertzaileen deskribapen solteak dira. Ez dago, halere, ezaugarri horren inolako azalpen zehatzik, azaleko proposamenez besterik. Deskribapen horietan subjuntiboko dakidan eta zekion adizkiekin parekatu izan da eta, beraz, * edin laguntzailetzat hartu. Halere, galdera asko sortzen ditu proposamen horrek.

Galdera horiek erantzuteko asmoz, saio honetan diakronikoki begiratzen zaio ezaugarriari. Garaian garaiko testuak aztertzen dira eta, batez ere, bertan agertzen diren indikatiboko NOR-NORI saileko adizkiei jartzen zaie arreta. Helburu nagusia da ezaugarriaren bilakabide diakronikoa gertuagotik ezagutzea eta, beraz, Nafarroako erdialdeko hizkerek duten ezaugarri hori berrikuntza bat den ala arkaismo bat den argitzea.

\section{Metodologia eta corpusa}

Ezaugarri horren datu ahalik eta zehatzenak eskuratu ahal izateko eta indikatiboko NOR-NORI saileko paradigmak Nafarroan izan duen bilakabidea ulertzeko, goi-nafarreraz idatzitako testuen azterketa sistematikoa egin dut; bereziki gaur egun ezaugarri hori dagoen edo historikoki egon den eskualdeetako testuak, hau da, Nafarroako hegoaldeko eta erdialdeko aldaeretan idatzitakoak izan ditut eskura.

Hauexek dira indikatiboko NOR-NORI saileko perifrasiak sakonago aztertzeko lagintzat hartu ditudan lekukotasunak:

- 1609ko olerki sarituak (Reguero 2019).

- Joan Beriainen meza entzuteko tratatua (1621) eta kristau dotrina (1626) (Reguero 2019).

— 1729ko goi-nafarrerazko lehen sermoia (Reguero 2019).

— Frantzisko Elizalderen 1735eko dotrina (Reguero 2019).

- 1743ko bi sermoi anonimo (Reguero 2019).

- 1745 inguruko Obanosko bertsoa (Reguero 2019).

- 1750eko eliza aginduaren Orrioko aldaera (Reguero 2019).

- Larrasoañako sermoi anonimo data gabea (Reguero 2019).

— Muruzabalgo zenbait sermoi: data gabe batzuk eta 1751 ko bi (Satrustegi 1987).

— Ororbiako sermoi bat (Satrustegi 1987).

- Markotegiren sermoia (Knörr 1992).

— Martinez Morentingo osaba-iloben 4 sermoiak (Lekuona 1973).

— XVIII. mende akabuko Utergako dotrina (Ondarra 1980).

- Lizarraga Elkanokoaren Urteko igande guztietako platika edo prediku laburrak (1990 [1802]), Doctrina christioarén cathechima (Lizarraga (1979 [1803]) eta Ongui iltzen laguntzeko itzgaiak (1994 [1807 b.l.]).

— xIx. mendeko (1833) Aralarko hiru sermoiak (Satrustegi 1987).

— Goldarazko hiru sermoi: bata $1833 \mathrm{koa}$, bestea $1834 \mathrm{koa}$ eta, azkena, $1839 \mathrm{koa}$ (Satrustegi 1987). 
Testu horietako agerraldi guztiak datu base batean sartu ditut azterketa errazte aldera, baina, horietaz gain, beste ikerketa eta lekukotasun batzuk ere baliatu ditut; esaterako, Gaminde (1985), Ibarra (1995, 2000), Artola (2012, 2014), Apalauza (2012) eta Camino (1999, 2000, 2001).

\section{Ezaugarriaren hedadura eta beste}

Zuazok (2008: 109) euskara nafarraren ezaugarritzat aurkeztu du indikatiboko NOR-NORI saileko adizkietan - $k i$ - agertzea: «NOR-NORI saileko adizkien iraganaldian -KI- erroa dago euskalkiaren eremu zabalean: zakidan 'zitzaidan', zakion 'zitzaion', zakigun 'zitzaigun."

Aipuan bertan irakur daitekeenez, ezaugarriak dialektoaren eremu zabala hartzen du; ez haatik osoa, eta eremutik kanpo ikusten ditu ipar-sartaldea eta Baztan. Caminok (2003: 455) zehaztasun gehiago ematen ditu ezaugarriaren hedadura geografikoaz. Ahozko zein idatzizko lekukotasunak aintzat hartuta, eremu hau ematen dio ezaugarriari: Gesalatz, Uterga (kristau ikasbidean), Goñerri, Burunda, Sakana erdialdea, Arakil, Oltza, Izarbeibar, Eguesibar, Imotz, Atetz, Ezkabarte, Odieta, Anue, Erroibar eta Artzibar.

Gamindek (1985) Nafarroan herriz herri jasotako datuetan nabarmen ikusten da bi formak erabiltzen direla. Besteak beste eta aldaerak aldaera, - $k i$-dun formak agertzen dira Etxarrin, Arruazun, Lizarragan, Unanuan, Dorraon, Lakuntzan, Arbizun, Uharten, Irañetan, Olatzagutian, Iturmendin, Erason, Muskitzen, Beuntzan, Beorburun, Gaskuen, Latasan eta Egozkuen.

Maiztasunak gorabehera, mapa honetan argiago ikus daiteke ezaugarriak duen hedadura geografikoa:

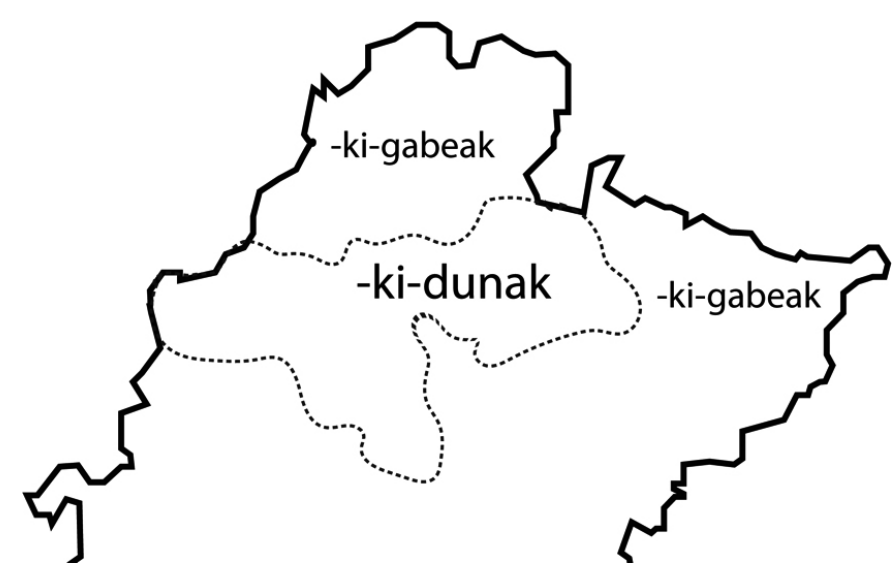

1. mapa

-ki-dun adizkien hedadura

Ezaugarria aztertzen ari garela, kontuan hartu behar da ondoko banaketa: herri/ eskualde batzuetan iraganean eta orainaldian agertzen da $-k i$-; beste batzuetan, or- 
dea, iraganean bakarrik. Arestiko herri zerrenda horretan, Olatzagutian, Iturmendin, Muskitzen, Beuntzan, Gaskuen, Latasan, Egozkuen eta Beorburun iraganeko formetan bakarrik agertzen da.

Burundan zaigu gisako adizkiak, -ki- gabekoak, orokorrak bide dira orainaldian; «Sakanako gainerako hizkeretan, ordea, Etxarri Aranaztik ekialdera, adizki bereziak erabiltzen dira; -KI- erroa daukatenak. Sakanan baizik ez dira entzuten horrelakoak: dakit 'zait', dakizu 'zaizu', dakio 'zaio', dakigu 'zaigu'...” (Zuazo 2010: 138-139).

Bestela ikusten du iraganean:

Iraganaldian, ordea, Nafarroan barrena hizkera askotan daude -KI- errodunak: $z a$ kiten / zekiden 'zitzaidan'. Horrelakorik ere ez dago Urdiainen, baina bai Iturmendin eta Bakaikun, eta Olatzagutian ere baziren 80ko hamarkadan (Gaminde 1985-I: 175 eta Irizar 1991). Francisco Ondarrak (2005: 493) Bakaikun bildutakoa da ondorengo adibidea: trena pasatu zakiten 'trena pasatu zitzaidan'. (Zuazo 2010: 138)

Nafarroako hizkerek erakusten duten errealitate horretatik, Zuazok ondorioztatzen du -ki- morfema Burunda osokoa izan zela iraganean, eta ondoren galdu egin zela Altsasun eta Urdiainen. Apalauzak (2012: 362) aztergai duen eremuaren, hots Nafarroako ipar-mendebaldearen, «eskuin muturrean» jaso ditu - $k i$-dun aldaerak, eta Oskotz eta Muskizko adibideak ematen ditu: gustatzen zaikien, tokatu zeikien, ematzen tzaikion, etzaikion botzen, gustatze zaikion, etzaikion gustatzen dira Muskitzen jasotako adibideak, eta tokatu zaikion eta gustetzen tzaikion Oskotzekoak.

\section{Zer diote testuek?}

Arestiko atalean ikusi dugu xx. mendeko lekukotasunek zer dioten indikatiboko NOR-NORI saileko adizkiez, baina garai zaharragoetan zer gertatu den ulertzeko testuei begiratzea ere ezinbestekoa da. Ondoko lerroetan garaiz garai ikusiko ditugu sail horretako aditzen agerraldiak. Aurrera baino lehen, ordea, komeni da kontuan izatea lekukotasunek badutela arazo bat. Dela testuen luzeragatik, dela testuen izaeragatik, batzuetan ez dago sail horretako aditzik eta agertzekotan ez da sail osoa agertzen. Batzuetan iraganeko adizki bakarra dugu, besteetan orainaldia baizik ez. Esate baterako, Nafarroa garaiko testuetan oso adibide gutxi aurkitu ditut NOR I. pertsona dutenak — natzaio adibidez-, eta gehienak dira egitura fosilduren batekoak. Gainera, -ki- duten perifrasi guztiak dira NOR 3. pertsona dutenak; beraz, horiez arituko naiz bereziki.

\subsection{XVI-XVII. mendeak}

Testuen izaera beragatik eta garai hartako lekukotasun gehienak laburrak direnez, NOR-NORI saileko adizkiak aurkitzea zaila da. Testu askotan ez da perifrasi hori agertzen; esaterako, Berako olagizonaren gutunetan (Reguero 2019: 219) edo Aldatzen 1609ko olerkian (Reguero 2019: 161) ez da sail horretako adizkirik.

Nafarroako NOR-NORI saileko adibide zaharrena 1506koa da eta Uitziko ezkontza fedean agertzen da: nayçacan 'natzaion'. Kasu honetan, ordea, ez da perifrasia, trinkoa baizik. Gainera, NOR 1. pertsona.

Nafarroako erdialdekoak bide dira Ezkurrak eta Elizaldek 1609an idatzi zituzten olerki sarituak (Reguero 2019: 156-167) eta NOR-NORI-ko indikatiboko adibide bana 
dute: emáten çáygu eta emanen çayo. Ikus daitekeenez, bietan -ki-rik gabeko orainaldiko formak agertzen dira. Bidenabarkoan, merezi du ohartaraztea Ezkurraren beste esaldi hau: guiçonári ematen dá. Esaldi horretako aditzean ez da datibo komunztadurarik.

Mende berean, baina zenbait urte geroago, Beriain utergarrak bi liburu idatzi zituen. Bata meza entzuteko tratatu elebidun bat da eta 1621 ean ikusi zuen argia. Bestea 1626an atera zen kristau dotrina da. Beriainek aitortzen duenez, Iruñeko euskaraz idatzita daude eta biak dira mende hartako Nafarroako lekukotasun luzeenak; beraz, interesgarria da bi lanak xeheki aztertzea.

1621 eko liburuari dagokionez, testu osoan indikatiboko NOR-NORI saileko 80 adizki aurkitu ditut, zeinetarik 10 bakarrik batira iraganekoak. Hauek dira sail horretako adibide batzuk: agradacen çayo, agradacen bayçat, guenduco çayzquio, eman ciçaygula, eldu cizayzquion. 80 adizki horietatik bakarra da subjektua 3. pertsona ez duena: confessacen nayçayo. Eta, ikus dezakegunez, ez iraganean, ez orainaldian, ez da -ki-morfemaren aztarnarik ikusten.

1626ko dotrinaz den bezainbatez, aurrekoan baino agerraldi gutxiago ditugu, baina bide berari jarraitzen dio: indikatiboko NOR-NORI saileko 43 adizki aurkitu ditut; guztiak dira orainaldikoak eta bakar batek ere ez du -ki-morfema. Hauek dira, besteak beste, Beriainen adibideak: emanen çayo, conveni çazquionac, conveni çayguna, adicen çayotenen. Bigarren liburu honetan ere, aurkitutako adibide guztiak NOR 3. pertsonakoak dira, bakarra izan ezik: confessacen nayçayo. Ohart gaitezen, bi liburuetan adibide bana dagoela 3. pertsonakoa ez dena, eta bietan fosilduriko forma bat agertzen da, konfesio jeneralean.

\subsection{XVIII. mendea}

Mende honetatik aurrera lekukotasun kopurua hazi egiten da eta eskualde gehiagotako testuak ditugunez, irudia ere aldatu egiten da; batez ere, XviII. mendearen bigarren erdialdetik aurrera.

Mende hartako testurik zaharrena 1729ko sermoia da (ik. Reguero 2019: 237). Otsagabian aurkitu arren, hegoaldeko goi-nafarrerazko hizkera bat erakusten du testuak, eta indikatiboko NOR-NORI saileko hiru adizki aurkitu ditut bertan: guertatcen zaigun, zor zaiola eta iduri zaicie. Bistan denez, hiruretan NOR 3. pertsona agertzen $\mathrm{da}$, orainaldikoak dira eta - $k i$ - gabekoak.

Antzeko irudia erakusten du 1735eko Elizalderen dotrinak. Hiru adibide besterik ez ditu; bata iraganekoa, beste biak orainaldikoak: conveni cizaigu, deicen zayo eta tocacen zaizquioten. Hirurak, beraz, -ki-rik gabekoak.

Mende horretan badira anonimoak diren hainbat sermoi. Horien artean batzuk Satrustegik jaso zituen. Nafarroako hango eta hemengo herrietan irakurritako sermoiak dira eta, anonimoak direnez, askotan zaila da jakiten nongoak diren, non agertu ziren jakin badakigun arren. Anonimoa izan arren nongoa den ezagutzen dugun sermoi bat da Larrasoañakoa. Satrustegik (1987: 57) xVIII. mende hasierakotzat dakar, testuen aurkezpenak kronologiari erantzuten badio behintzat, baina Reguerok (2019: 570) zalantzazkotzat harturik liburuko eranskinean gehitzen du. Sermoi horretan bi aldiz agertzen dira NOR-NORI saileko adizkiak, biak iraganekoak eta biak - $k i$ rekin: eman cequion eta iruditu cequio. 
Nafarroako Muruzabalen aurkitu ziren xviII. mendearen erdialdeko hainbat eta hainbat sermoi, gehienak anonimoak dira, batzuek urterik ez dute eta hizkera aldetik ez dira homogeneoak; ondorioz, dialektologia egiteko ez dira guztiz fidagarriak. Edonola ere, ezaugarrien kronologia egiteko interesgarri izan litezke.

Sermoi horietako bat da Pasce oves meas batekin hasten den prediku data gabe anonimoa (Satrustegi 1987: 70). Itxura guztien arabera hegoaldeko goi-nafarrerako hizkera batekoa da — besteak beste, iraganeko adizkiek ez dute - $n$-rik - eta NOR-NORI-ko adizki hauek aurkitu ditut:

1. taula

NOR-NORI-ko adizkiak Pasce oves meas sermoian

\begin{tabular}{ll}
\hline \multicolumn{1}{c}{$\boldsymbol{k} \boldsymbol{i}$ - gabeak } & \multicolumn{1}{c}{$\boldsymbol{k} \boldsymbol{k}$ - dutenak } \\
\hline $\begin{array}{l}\text { correspondituco zaioten } \\
\text { encomendazen zayo }\end{array}$ & joan zenquion \\
sostatu zizaion & \\
ofrecicen zayoten & \\
asqui zaide & \\
\hline
\end{tabular}

Ikus daitekeenez, orainaldian beti erabiltzen du -ki-gabekoa (zaioten, zayo, zaide); iraganean, txandaketa dago: zizaion, baina cenquion, zequio. Ez da erraza txandaketa horren arrazoia ezagutzen; batetik posible da garaiko errealitatearen isla izatea eta bi forma erabiltzea herrian, baina bestetik, posible da prestigio kontuak ere egotea atzean. Besteak beste det gisako adizkiak agertzen dira hizkeragatik dut esperotako lekuan eta horren gisakoekin batera; beraz, agian gipuzkeraren prestigioa egon daiteke bai det gisako adizkien atzean eta baita iraganeko - $k i$ - gabeko adizki horien atzean ere.

Bilduma bereko $1751 \mathrm{ko}$ bi sermoiak aztertu eta hauxe aurkitu dut: etorri zequiola, etorri baldimbazequio batean; bestean, manifestatu ceiquiotela, zor zeyotenac, c(on)veni zeiotena, escapacen daquio. Hamarkada bereko beste hiru sermoi ezagutzen ditugu, Oltza zendeako Ororbian irakurri zirenak. Horietako zaharrenean, 1756koan, hauexek datoz: aparecitu ceiquio, apareçitu çeiquio, atraco daquizquizu, iten daquizquigun, arrimecen ceionari, aparecitu ceiquio eta assi ceiquio. $1751 \mathrm{ko}$ bigarrengoan eta $1756 \mathrm{ko}$ honetan, bietan agertzen da - $k i$ - morfema orainaldian zein iraganean; halere, txandaketa dago orainaldikoan.

Mendearen akabukoa da Utergako dotrina eta bertan indikatiboko NOR-NORI saileko bi adizki agertzen dira: pertenecicen daquio, confesacen naio. Lehenengoa NOR 3. pertsonari dagokion adizkia da, eta $-k i$ - morfema darama orainaldian. Bestea ere orainaldikoa da, baina NOR 1. pertsona da. Bi adibide izan arren, biak dira biziki interesgarriak. Kontuan izan behar dugu dotrina hau idatzi baino mende eta erdi lehenago, herri horretako seme zen Juan Beriainek bi liburu idatzi zituela, eta lan horietan ez bezala, dotrina honetan $-k i$ - agertzen da orainaldian. Gainera, nayçayo du Beriainek; dotrina honetan, aldiz, naio agertzen da, -tza-rik gabe. ${ }^{2}$

${ }^{2}$ Ez da aise jakiten naio hori «zaio» formaren analogiaz sortua den, «natzaio» laguntzailearen ordezko hutsa den ala beste arrazoiren bat ote dagoen atzean. 


\subsection{XIX. mendea}

Nafarroako xIx. mendeko autore esanguratsuenetakoa, zalantzarik gabe, Lizarraga Elkanokoa da. Milaka eta milaka orrialde utzi zituen hegoaldeko goi-nafarrerazko Esteribar inguruko mintzoan idatzirik. Testu horiek bere osotasunean aztertzea lan mardula da eta saio honen mugak gainditzen ditu. Hori dela eta, lagin moduan hartu ditut Urteko igande guzietarako prediku laburrak (1802 [1990]), Doctrina christioarén cathechima (1803 [1979]) eta Ongui iltzen laguntzeko iztgaiak (1807 b.l. [1984]).

Lan horietan bistakoa da joera. Orainaldian -ki-gabeko aldaerak erabiltzen ditu: ematen záio, barcatzen zaizquizu. Aldiz, iraganean -ki-dunak dauzka: etorri zequigun, etzequio errevelátu.

Satrustegik (1987) Done Mikel Aralarkoaren santutegian aurkitutako hiru sermoi argitaratu zituen; guztiak dira Sakana inguruko euskaraz idatzitakoak. Horietako batean, 1833koan, hauexek ditugu: tocacen daquiyo, ezpadaquio faltacen, eguiten daquiyo, ateratzen daquiyo, iduritu cequiyon, tocacen zaiyoc, correspondicen daquiyuen, gustacen zait. Alegia, - $k i$ - erabiltzen du orainaldi zein iraganaldian, baina itxuraz orainaldian txandaketa dago eta zait ere agertzen da.

Sakanatik ipar-ekialdera dagoen Imozko Goldaratz herrikoak bide diren sermoi batzuk ere jaso zituen Satrustegik (1987) lan berean. Prediku horiek aurrekoarena bestelako irudi bat eskaintzen dute. Hiru sermoietan, guztira indikatiboko NOR-NORI saileko 31 adizki aurkitu ditut, zeinetarik 3 bakarrik baitira iraganeko adizkiak. Orainaldiko guztiak - ki-gabeak dira; iraganaldikoez den bezainbatez, sermoi batean bi aldiz cizaion agertzen da, beste batean etorri cequizquion. ${ }^{3}$

\subsection{XX. mendea}

Caminok (1999, 2000 eta 2001) Goñerriko euskara aztertu zuen Ondarrak (1993a, 1993b, 1994 eta 1995) ezagutzera emandako lekukotasunak baliatuz eta datu berriagoak erabiliz. Lan horietako batean halaxe dio:

Nor-Nori aditz saileko iraganeko nahiz oraineko adizkietako - $k i$ - artizkia eremu honetako hizkeren ezaugarri nabarmena dugu. Ezinbestean garai oso desberdineko datuak baliatzen ari garenez, diatopia eta diakronia nahasten ahal zaizkigu, eta ondorio dialektologiko okerretara irits gaitezke. Dena den, hizkera guztietan xIx. mendean oraineko adizkietan ez agertzea aipagarria dela uste dugu.

Iraganeko aldaeretan mendiaz bi alderdietan dugu; hona mende honetako Andimendiaz bestaldeko adibide batzuk: zaki(g)un «zitzaigun» (Lizarraga, Etxarri, Arruazu), zakion (Irañeta), zakion (Ihabar) eta zaikion \& zaion «zitzaion» (Urritzola). Andimendiaz harat, berriz, xIx. mendeko bigarren erdialdeko Oltzako eta Gońiko zekide \& zekire "zitzaidan» nahiz Gesalazko Muzkiko XviII. mende bukaerako cer guertatu cequio "zitzaion» aipa ditzakegu. Eguesibarren eta Garesen ere zekio dakar Bonapartek. Erdialdetik Imozko Eraso eta Muskitzera, Atezko Beuntzara, Ezkabarteko Anotzera, Odietara eta Anue ibarreko Egozkue eta Leazkuera hedatzen da eta ekialdetik Erroibar edo Artzibarreraino, baina ez Aezkoara. (Camino 2000: 152)

3 Mende berean Miguel Ignacio Armasa labaiendarrak idatzitako sermoian egondu zaquiolaric 'egondu zitzaiolarik' agertzen da, salbuespen gisa (Lekaroz 2014). 
Iparralderaxeago, Nafarroako ipar-mendebaldeko hizkerak aztertzen dituelarik, Apalauzak (2012) Imozko bi herritan jaso ditu perifrasi horren laginak. Koldo Artolak (2012) Artzibarren jasotako lekukotasunetan zekiren 'zitzaidan' jaso zuen; halere kontuan izan behar dugu hiztuna (Joakin Garrues) Esteribarko Ilurdotz herrikoa zela. Beraz, ez bide da Artzibar osora heldu berrikuntza, iraganean $-k i$ - gabekoak agertzen baitira (Artola 2014). Ibarrak (1995) Ultzamaldeko adibideak aurkeztean -ki-gabeko formak ematen ditu, bai orainaldian bai iraganean; halere, iraganean - $k i-$ Erason, Muskitzen (Imotz), Beuntzan (Atetz) eta Lantzen, Egozkuen eta Leazken (Anue) aurkitu ditu (Ibarra 1995: 425-426). Esteribarren eta Erroibarko Lintzoainen ere -ki- atzizkidunak dira nagusi iraganeko formetan (2000: 180); aldiz, Erroibarko gainerako herrietan eta Artzibarren - $k i$ - gabeak dira nagusi bai iraganaldian bai orainaldian (2000: 181).

\section{Arkaismo ala berrikuntza? Ezaugarri berri baten proposamen berria}

Lan honek, berez, dialektologia saio bat izan nahi du, baina dialekto zehatz baten ezaugarri zehatz bat besterik ez da hartzen kontuan. Caminok inoiz adierazi izan du «dialektologiaz dihardugunean kronologiaz jardun behar» dugula:

Dialektologiaz dihardugunean kronologiaz jardun behar dugu baitezpada, hizkuntzaren historia eta dialektoen azterketa uztarturik baitaude. Alderdi kronologikoari dagokionez hizkuntza-ezaugarriak bereizteko ohiko sistemari heltzea gauza beharra du dialektologiak: zuzen eta bidezko da ezaugarriak berrikuntza / hautu / arkaismo banaketaren arabera aztertzea. (Camino 2008: 209)

Oro har, dialektologian hizkera baten ezaugarriak hirutan banatzen dira: berrikuntzak, arkaismoak eta hautuak. Halere, ikerketa sakonagoen ondoren batzuetan hautuak berrikuntzen kategoriara pasatzen dira (cf., adibidez, Camino 2009: 404; Ulibarri 2015: 40-41).

Ikusi dugu Caminok aldarrikatzen duela dialektologiaz aritzean kronologiaz aritu behar dela. Bide horretatik jarraituz, ezaugarri batez ari garenean ere kronologiaz aritu behar dugu, eta biziki emaitza interesgarriak lortzen dira ezaugarriak denboraren ardatzean jartzen baditugu. Sinkronikoki dialekto batek duen egoera eta dituen txandaketa fonetiko, morfologiko edo sintaktikoak aldaketa diakronikoen emaitza dira. Horregatik ezaugarri bat xeheki aztertzeak laguntzen du dialekto(ar)en bilakabidea hobeto ulertzen. Euskararen kasuan, Padillak (2013), esaterako, xeheki aztertu ditu ekialdeko hizkeretan agertzen den *iron aditz laguntzailearen agerraldiak eta aditzaren atzerakada azaldu du. Zuloagak (2017) beheko bokalaren itxiera aztertzen du eta ondorio diakroniko eta geografiko interesgarriak atera. Reguerok (2018) hegoaldeko *erazan aditz laguntzailearen hedadura eta kronologia zabaldu ditu. Berriki Leturiagak (2020) diozka eta dio gisako adizkiek Gipuzkoan dituzten agerraldiak eta bilakabidea aztertu ditu, bai kronologikoki, bai geografikoki.

Azken finean, dialektoek eskaintzen dituzten datuek hizkuntzaren bilakabidea hobeto ulertzen laguntzen dute. Rallik (2009), besteak beste, greziera modernoko dialektoak aztertu ditu, estandarrean ez diren ezaugarriak hobeto ezagutzeko:

Moreover, I have demonstrated that dialects can throw light on change and language variation, since a number of morphological items and various patterns, which 
may be found in certain dialects, are not part of the relevant standard varieties. (Ralli 2009: 103)

Bistan da, sinkronikoki begiratzen badugu, $-k i$ - morfemadun adizkiak erabiltzea edo ez erabiltzea Nafarroako hizkera batzuek egindako haututzat har daiteke, baina dialektologia historikoan sakonduko badugu, ezaugarri hori xehetasun handiagoz aztertu behar da arkaismo den ala berrikuntza den ebazteko.

Egiari zor, gutxi esan izan da, orain arte, ezaugarri honen historiari buruz. Hegoaldeko goi-nafarrera aztertzen duen saio batean, Aldaik (1999: 267) «arkaismo baten kontserbazio partzial» bat dela proposatzen du; areago, ohartarazten du «epealdi labur xamarraren buruan kontrako norantza duten bi aldaketa proposatu behar» genituzkeela: lehenengo aoristoa galtzea eta, ondoren, aoristoan oinarriturik NOR-NORI saileko adizkietan berrikuntza gertatzea. Antzeko bidetik, Reguerok (2020: 627) XVI-XVIII. mendeetako lekukotasunak aztertu ondoren dio ezen «arkaismoa baino gehiago, arkaismo batetik abiatutako berrikuntza konplexuago baten aurrean egon gintezke[ela]»; halere, ikerketa sakonagoaren beharra azpimarratzen du.

Arestian ikusi ditugu lehen testuetatik aurrera indikatiboko NOR-NORI saileko adizkien agerraldiak eta, batez ere, arreta berezia jarri dugu $-k i$-dun laguntzaileetan. Behin hori ikusita, ondoko lerroetan ahaleginduko naiz azaltzen zergatik - $k i$ - hori erabiltzea ez den arkaismo bat eta ez datorren aoristo batetik:

1. Nafarroako testu zaharretan ez da aoristorik lekukotzen, Isastiren errefrauetako laginaz landara. Testu gutxi izateak eragin lezake horretan, baina indikatiboko iraganeko xvi. mendeko adibideetan bakar bat ere ez da aoristo. Beraz, ematen du goi-nafarrera izan zela aoristoa galtzen lehena eta XvI. menderako ez zela halakorik. ${ }^{4}$

2. Ez da testu zaharrenetan -ki-dun adizkirik agertzen, nahiz eta kokapen geografikoagatik espero litekeen; aitzitik, bestelakoak agertzen dira. Beriain eta Elizalde dira horren lekuko. Ezaugarriaren lehen agerraldiak xvıII. mendearen erdialdekoak dira.

3. Dakigunez, aoristoa perfektua da. Aldiz, NOR-NORI-ko saileko iraganeko - $k i-$ dun perifrasietan forma burutua (partizipioa), burutugabea (-ten, -tzen) eta geroaldia $(-k o,-e n)$ agertzen dira. Areago, aoristoan, oro har, aditzoina erabiltzen da, baina datu basea osatzeko erabilitako testuetan ez dago - $k i$ - morfemadun perifrasirik aditzoina darabilenik, ezta indikatibokoak ez diren perifrasietan aditzoina eta partizipioa bereizten dituzten testuetan ere.

4. Aoristotik datorren ezaugarria dela defendatuz gero, azaldu beharko litzateke zergatik orainaldian ere agertzen den, - $k i$ - ezaugarria duten lehen testuetatik agertzen baita.

Indikatiboko forma horiek subjuntiboko formetatik datozelako ideia ere bazter liteke; alegia, ez dirudi subjuntiboko etor dakion $\rightarrow$ etorri dakio $\rightarrow$ etorriko / etortzen dakio gertatu denik. Bybee, Perkins eta Pagliucak (1994: 230-236) erakusten dutenez, tipologikoki arrunta da subjuntiboaren etorkietako bat izatea indikatiboa, baina

\footnotetext{
${ }^{4}$ Gipuzkera zaharrean ere orain arte ez da aoristorik aurkitu; Azkoitiko olerki liriko aurkitu berrian, ordea, aoristoa agertzen da (Ariztimuño 2020 [2022]).
} 
ez alderantziz. Euskaraz ere halaxe izan dela dirudi: subjuntiboan erabiltzen diren *ezan eta *edin indikatiboan agertzen ziren xvI. mendean eta oraindik ere arrasto fosildua dago etor dadinean 'etortzen denean' edo egin dezanean 'egiten duenean' gisako mendeko perpausetako egituretan.

Nondik ez datorren esanda, hurrengo pausoak behar luke izan azaltzea nondik etor litekeen berrikuntza hori. Goraxeago ikusitako arrazoiak aski izan litezke -ki-dun laguntzaileak *edin aditzaren formak direlako ideia baztertzeko. Har dezagun sail horretako adizki bat eta segmenta dezagun:

(1)

$$
\begin{array}{lll}
D a- & -k i- & -t \quad \text { 'zait' } \\
? & \text { DAT. FLAG } & \text { I.SG.DAT. }
\end{array}
$$

Atzetik hasita, azken morfema datiboko pertsonaren marka da, izan laguntzailearen adizkiekin gertatzen den bezala: zait dakit, zaio dakio. Erdian agertzen den -ki- hori Traskek (1997) «dative flag» izendatu zuen datibo marka besterik ez da. Daedo iraganeko ze(n)- zer den azaltzea da, beharbada, zailena. Halere, izan aditzaren 3. pertsonako aditzaren aurrean egon gaitezkeela dirudi: alegia da eta zen aditz formei - $k i$ - datibo marka eta datiboko pertsona komunztadura gehituta sor zitekeen paradigma berria.

Gertakari horrek badu paralelismorik euskaraz. Baldin eta

(2)

$$
\begin{array}{ll}
\text { dator }- \text { datorkio } & \text { zetorren }- \text { zetorkion } \\
\text { dago }- \text { dagokio } & \text { zegoen }- \text { zegokion }
\end{array}
$$

baditugu, eredu berari jarraituz sortuak izan litezke

$$
\text { da - dakio zen - zekion (zenkion ere badago) }
$$

Horrela azal liteke zergatik, besteak beste, -ki- NoR singularreko 3. pertsonan bakarrik agertzen den: dakit badago baina ${ }^{* *}$ nakio ez. ${ }^{5}$

Bestalde, proposamen honek aoristotik datorrelako hipotesiak dituen arazoak gainditzen ditu: batetik, azaldurik geratzen da zergatik burutu zein burutugabean agertzen den eta, bestetik, azaldurik geratzen da orainaldian ere agertzea.

Beraz, proposamen berriaren arabera, Nafarroako erdigunean berrikuntza bat gertatu zen NOR-NORI saileko indikatibo adizkietan eta paradigma aldatu zuen: osorik batzuetan, hau da, orainaldian eta iraganaldian; erdizka besteetan, iraganean bakarrik. Hori da, beharbada, azaltzen gaitzena.

Pluraleko formez den bezainbatez, datozkio eta dagozkio adizkietan ikusten dena $\mathrm{da}$, - batez ere bigarrengoan — singularreko adizkiak hartu direla oinarri (dator eta dago; ez daude, ${ }^{* *}$ daudekio) eta NOR plurala den kasuetan -z- pluralgilea gehitu dela.

5 Etorri eta egon aditzekin NOR 3. pertsonakoak ez diren adibideak ditugu: nagokio eta nagokizu darabilte, adibidez, Lizarraga Elkanokoak eta Mendiburuk eta natorkizu Mendiburuk. Interesgarri izan liteke adizki horien kronologiei (edonola ere, ez dirudite oso zaharrak) eta hedadurei ere begiratzea ondorio sakonagoak ateratzeko, baina agian bi aditz horien kasuan berrikuntza urrunago heldu zen, paradigma osoari eragiteraino. 
Izan-en kasuan, aldiz, -zki- da pluraleko marka: dakio dakizkio; zekio(n) - zekizkio(n). Hori ere azaldu beharko litzateke, baina dizkio gisako aditz laguntzaileen analogiaren bidez azaltzea ez da, berez, zaila. Edo, agian, datozkio eta dagozkio gisakoetan haplologia daukagu: * datozkikio-tik lehena eta *datozkikio-tik bigarrena; aldiz, dakizkio-ren eta gisakoen kasuan ez da halakorik, beharbada, *eradun-eko dazkio eta gainerakoekin sinkretismoa saihesteko.

Saioaren hasieran aipatu dut $-k i$ - duten hizkeren artean aldakortasuna dagoela: batzuek iraganean bakarrik dute; beste batzuek, ordea, orainaldi eta iraganean dute -ki-. Goñerriko hizkeraz ari dela, gorago emandako Caminoren aipuan esaten da Gońerrin ohikoa dela -ki- artizkidunak aurkitzea eremu hartan, bai orainaldian bai iraganaldian. XviII. mende akabuko Utergako dotrinan dagoen adibide bakarra orainaldikoa da eta XIx. mendean Sakanako lekukotasunetan maiz agertzen da orainaldian eta iraganaldian. Hortik iradoki daiteke ezaugarria XvIII. mendearen erdialdean sortu zela Nafarroako mendebaldean, Andimendi inguruan, Gesalatz, Goñerri eta Sakana artean, eta handik hedatu zela Nafarroako erdialdera. Beharbada, lehenengo iraganeko adizkietan egin zen berrikuntza, eta handik hedatu zatekeen orainaldira. Halere, gune berritzailetik kanpo hedadura murritzagoa izan du ezaugarriak eta iraganeko adizkiek baizik ez dute egin berrikuntza.

Proposamena ontzat hartuz gero, beraz, ez dago inolako loturarik ez aoristoarekin ez subjuntiboan agertzen diren adizkiekin, eta sinkretismoa gertatu da sail bateko eta besteko adizkien artean. Eta, hala balitz, Lehen Goi-nafarrera Modernoa Goi-nafarrera Zaharretik bereizteko ezaugarritzat ere har liteke.

\section{Ondorioak}

Saio honetan, dakidala, lehen aldiz goi-nafarreraren ezaugarri nabarmenetako baten kronologia egiten da arkaismo ala berrikuntza den jakin ahal izateko. Orain arte ez da saio monografikorik egin ezaugarria aztertzeko, baina ikerlariek aho batez onartu dute goi-nafarrerako indikatiboko NOR-NORI saileko - $k i$-dun laguntzaileak aoristo baten aztarna direla (ik. Aldai 1999). Are gehiago, Reguerok (2020: 627) proposatzen du «arkaismo batetik abiatutako berrikuntza konplexuago baten aurrean egon gintezke[ela]».

Saio honetan hipotesi berri bat proposatu da, eta horren aldeko argudioak aurkeztu dira. Zenbait arrazoi eman dira erakusteko indikatiboko NOR-NORI saileko dakit eta zekion gisakoak ez direla arkaismo eta ez datozela lehenagoko aoristo batetik edo subjuntiboko formetatik; aitzitik, izan aditzaren indikatiboko da eta zen 3. pertsonako adizkietatik sortutako aditz laguntzaileak direla defendatzen da, eta gehitzen zaien - $k i$ - artizkia beste aditz batzuetan agertzen den datibo marka besterik ez litzateke. Proposamenaren aldeko argudiotzat hartu dira, bestek beste, ${ }^{* *}$ nakio modukorik ez egotea, $-k i$-dunak orainaldian eta lehenaldian agertzea eta biak batera hastea lekukotzen. Halaber, ideia berri honen alde egin dezake perifrasiko aditz nagusia burutu, burutugabe eta geroaldiko formetan agertzeak, eta inoiz ez aditzoinarekin aoristoan bezala. Beraz, ondorioztatzen da Nafarroako eskualde batzuek egin duten berrikuntza dela. 


\section{Bibliografia}

Aldai, Gontzal. 1999. Hegoaldeko goinafarrera zaharra: aditz laguntzaileekiko ezaugarri zenbait. FLV 81. 263-274.

Apalauza, Amaia. 2012. Nafarroako ipar-mendebaleko hizkeren egitura geolinguistikoa. Iruñea \& Bilbo: Nafarroako Gobernua \& Euskaltzaindia.

Ariztimuño Lopez, Borja. 2020 [2022]. Ohar filologikoak Azkoitiko testu aurkitu berriaz: irakurketa proposamena. ASJU 54(1-2). https://doi.org/10.1387/asju.23317.

Artola, Koldo. 2012. Artzibarko aldaera deitu izanaren inguruan (5 - Hego-Esteribarko laginak: Ilurdotz I). FLV 114. 5-60.

Artola, Koldo. 2014. Artzibarko aldaera deitu izanaren inguruan (eta 9 - Aditzaz zerbait Elkanoko aldaerarekiko erkaketan). FLV 118. 393-435.

Bybee, Joan, Revere Perkins \& William Pagliuca. 1994. The evolution of grammar. Tense, aspect, and modality in the language of the world. Chicago \& Londres: University of Chicago Press.

Camino, Iñaki. 1999. Goñerriko hizkera (I). ASJU 33(1). 1-74.

Camino, Ińaki. 2000. Gońerriko hizkera (II). ASJU 34(1). 137-196.

Camino, Ińaki. 2001. Goñerriko hizkera (III). ASJU 35(2). 445-509.

Camino, Ińaki. 2003. Hego-nafarrera. Iruñea: Nafarroako Gobernua.

Camino, Ińaki. 2008. Dialektologiaren alderdi kronologikoaz. FLV 108. 209-247.

Camino, Ińaki. 2009. Dialektologiatik euskalkietara tradizioan gaindi. Donostia: Elkar.

Gaminde, Ińaki. 1985. Aditza ipar goi nafarreraz, 3 lib. Iruñea: UEU.

Ibarra, Orreaga. 1995. Ultzamako hizkera. Inguruko euskalkiekiko harremana. Iruñea: Nafarroako Gobernua.

Ibarra, Orreaga. 2000. Erroibarko eta Esteribarko hizkera. Iruñea: NUP/UPNA.

Knörr, Enrike. 1992. Un sermón de Martín Joseph Marcotegui, de Goñi, predicado en Ollo (1777). In Luis Villasanteri omendaldia (Iker 6), 223-242. Bilbo: Euskaltzaindia.

Lekaroz, Gorka. 2014. Basaburua Txikiko euskararen lekukoak (I). FLV 118. 247-278.

Lekuona, Manuel. 1973. Textos vascos del s. xvin en tierra de Estella. FLV15. 369-390.

Leturiaga, Olatz. 2020. Gipuzkoa erdialdeko pluralgileen azterketa. In Ińaki Camino, Xabier Artiagoitia, Irantzu Epelde \& Koldo Ulibarri (arg.), Eibartik Zuberoara euskalkietan barrena. Koldo Zuazori gorazarre, 367-402. Bilbo: UPV/EHU.

Lizarraga, Joakin «Elkanokoa». 1979 [1803]. Doctrina christioarén cathechima I. Fede christioarén gáin. Iruñea: Nafarroako Diputazioa, Principe de Viana \& Euskaltzaindia (Juan Apececheak paratua).

Lizarraga, Joakin «Elkanokoa». 1984 [1807 b.l.]. Ongui iltzen laguntzeco itzgaiac. Bilbo: Euskaltzaindia (Frantzisko Ondarrak paratua).

Lizarraga, Joakin «Elkanokoa». 1990 [1802]. Urteko igande guzietarako prediku laburrak. Bilbo: Euskaltzaindia (Frantzisko Ondarrak paratua).

Ondarra, Frantzisko. 1980. Catecismo del siglo Xviı en vasco de Uterga (Valdizarbe). FLV 35-36. 173-222.

Ondarra, Frantzisko. 1993a. Goñerrin aurkitutako testuak (IX). ASJU 27:1. 299-320.

Ondarra, Frantzisko. 1993b. Goñerrin aurkitutako testuak (X). ASJU 27:3. 903-948.

Ondarra, Frantzisko. 1994. Goñerrin aurkitutako testuak (VI). FLV 67. 521-554.

Ondarra, Frantzisko. 1995. Goñerrin aurkitutako testuak (VII). FLV 68. 173-190.

Padilla, Manuel. 2013. Euskararen laguntzaile ahantziaz: *iron aditzaren historia. FLV 116. 131-170. 
Ralli, Angela. 2009. Morphology meets dialectology: insights from Modern Greek dialects. Morphology 19(1), 87-105.

Reguero-Ugarte, Urtzi. 2018. NOR-NORI-NORK saileko perifrasietako aditz laguntzaileak goi-nafarreraz: azterketa eta proposamen berria. ASJU 52(1-2). 682-694. https://doi. org/10.1387/asju.20224. (= Joseba A. Lakarra \& Blanca Urgell (arg.), Studia philologica et diachronica in honorem Joakin Gorrotxategi. Vasconica et Aquitanica. Gasteiz: UPV/EHU).

Reguero-Ugarte, Urtzi. 2019. Filologiatik dialektologiara Nafarroako testu zaharretan barrena (1416-1750). Bilbo: UPV/EHU.

Reguero-Ugarte, Urtzi. 2020. Euskara nafarrari diakroniatik begira. In Ińaki Camino, Xabier Artiagoitia, Irantzu Epelde \& Koldo Ulibarri (arg.), Eibartik Zuberoara euskalkietan barrena. Koldo Zuazori gorazarre, 617-630. Bilbo: UPV/EHU.

Satrustegi, Jose María. 1987. Euskal testu zaharrak I. Iruñea: Euskaltzaindia.

Trask, Larry. 1997. The history of Basque. Londres \& New York: Routledge.

Ulibarri, Koldo. 2015. Dotrinazko Sermoitegia: galduriko hizkerak eta dialektologia historikoa. Gasteiz: UPV/EHUko doktorego tesia. https://addi.ehu.es/handle/10810/15971.

Zuazo, Koldo. 2008. Euskalkiak. Euskararen dialektoak. Donostia: Elkar.

Zuazo, Koldo. 2010. Sakanako euskara. Burundako hizkera. Iruñea: Nafarroako Gobernua \& Euskaltzaindia.

Zuloaga, Eneko. 2017. Beheko bokalaren asimilazioaren historiarako: mendebaleko lekukotasunak. FLV 123. 167-199. 
